not with the Greek alphabet, which was of Phœnician, and ultimately of Egyptian, origin. And how are the Knôssian characters more advanced in type than the cuneiform characters? Obviously they are nothing of the kind ; they are in the same stage of development as the Egyptian hieratic writing, to which they bear a strong resemblance ; so far, then, it may be said that they are "ahead" of the Egyptian hieroglyphs; but cuneiform was far more conventionalised, far "ahead" of either Egyptian hieroglyphic and hieratic or Mycenæan linear. The people who used the Knôssian script may turn out to have had not one drop of Aryan "European" blood in them, and European-Greek culture may be as thoroughly of non-Aryan (and equally non-Semitic) origin as Semitic culture was in its origin absolutely non-Semitic.

The work of Mèssrs. Evans and Hogarth at Knôssos has been supplemented by the latter with the very interesting results of his excavation of the famous cave of Zeus on Mount Diktê, an account of which appears on p. 94, ff. Mr. Hogarth's story of his operations, of the blasting of the rocks, the unveiling of the most ancient
sanctuary of Zeus, the recovery of small bronze doubleaxes and other votive objects, belonging to the same period as the Knôssian palace, from the crevices of the stalagmitic deposit in which they had remained undisturbed for nearly four thousand years, the finding of a little Egyptian bronze statuette of Amen-Ră, which shows that somewhere about Iooo B.C. King Zeus was already identified with Amonrasuntiru, Amen-Rā, king of the gods be recommended to the notice of students of Greek religion.

It remains to speak of the articles of less importance which also find a place in this number of the Annual. That by Mr. F. B. Welch on "The Influence of the Ægean Civilisation on South Palestine " is important as chronicling the occurrence of Mycenæan pottery at a Palestinian site, Tell es-Safi. "This," says Mr. Welch, "was certainly a Philistine stronghold, a fact which is suggestive in view of the probable north-western origin of the Philistines" (p. I I9). This is quite true, and it may be remarked that the old tradition of the Cretan origin of the Philistines has lately, in view of the Egyptian records of attacks by the Peoples of the Sea, among whom figure the Pulesatha or Philistines, and a great deal of other evidence, both archæological and legendary, come once more to the front, and probably represents a historical fact. But Mr. Welch should note that Semitic authorities such as Delitzsch, Jensen, Mayer and Tiele uncompromisingly claim the Philistines as Semites, and specifically Aramæans. The Egyptian evidence, however, as Mr. Welch rightly implies, goes absolutely against the Semitic claim, which will probably have to be given up. Still, the Greek archæologists have no right to ignore the opinion of the Semitists on such a question as this. Mr. Welch seems, by the way, to attach rather too much importance to purely "typological" arguments derived solely from the study of pottery, which can never be an absolutely infallible guide.

Mr. J. C. Lawson's note on "A Beast-Dance in Scyros" (p. 125) will be of great interest to anthropologists. In carnival time the young men of Scyros array themselves in goat-skin capes-" each does his best according to his lights and his means to look like a goat "-hang goat-bells round their persons and solemnly dance through the town, often stopping "at some friendly door to imbibe spirituous encouragement to further efforts." This is undoubtedly a very ancient survival, and possibly goes back to Mycenæan times, a surmise with which anybody who knows what a great part goat-headed and other theriomorphic figures play in Mycenæan art will probably agree. But alas, "thanks to the steadily increasing NO. I 644, VOL. 64] influx of Western culture during the last few years," the goat-mask is often replaced nowadays by " an Ally Sloper mask"! The modern Japanese wears a billycock or a deerstalker on the top of his national historical costume. So the free and upright civilisation of modern Europe dominates the world!

It may be finally noted that the knowledge which the contributors to this number of the Annual possess of the German language appears to be defective. If German terms are used at all, their proper plural forms should be given to them. "Buigelkannes" may be Dutch, but is neither German nor English; Mr. Welch gets over the difficulty, which might have been solved by reference to a German grammar, by giving his German words no plural form at all. He speaks of "Bügelkanne" and "Schnabelkanne" when he means Bügelkannen and Schnabelkannen.

Despite these little imperfections, the sixth number of the Annual of the British School at Athens is undoubtedly the most important contribution to our knowledge of the early history of mankind that has appeared for many years.

\section{MAGNETIC OBSERVATIONS DURING TOTAL SOLAR ECLIPSE.}

THE effect produced by a solar eclipse on the meteorological conditions of the atmosphere has on many occasions in the past been the subject of observation, but in the number of Terrestrial Magnetism just received we find an account ${ }^{1}$ of a systematic examination of the influence of such an eclipse on magnetic conditions also. It had appeared to Dr. Bauer, chief of the U.S. Magnetic Survey, that magnetic observations might on such an occasion be usefully undertaken; and the occurrence of the solar eclipse of May 28 of last year, the total phase of which was visible in the United States, afforded an excellent opportunity of carrying such design into execution. For the needs of the magnetic survey simultaneous magnetic observations are made on certain days throughout the year at the different magnetic stations, and it was arranged that such observations should be made, on the day of eclipse, at stations as near as possible to the path of totality. Six stations were selected ; three of them--Union Springs, Rocky Mount and Cape Charles - were situated within the path of totality, the remaining three-Salem, Bayard and Gaithersburg-being outside. The observers received instructions to occupy such stations as their special work permitted for the due accomplisbment of the object in view, accompanied by a detailed scheme of the observations to be made. The prescribed course was carried out by all the observers excepting the one at Gaithersburg, who for some reason failed to receive his instructions in time; but he made observations according to directions sent him previously, relating to other work. The detailed scheme of observa. tions is given with the view of aiding observers making preparations for similar work on future occasions. The observations made are discussed at considerable length, being accompanied by numerous graphical illustrations, and it is stated that there can be no question that some kind of magnetic disturbance made itself felt on May 28 at every one of the stations.

Finally, the conclusions arrived at are given under eleven separate heads, the principal points of which are contained in the following summary :-A small magnetic oscillation made itself felt at various stations situated in the eastern part of the United States during the time of the eclipse. It was detected by various persons, at various stations, with different instruments, under different conditions, and was also automatically recorded.

1 Résumé of magnetic observations made chiefly by the United States Coast and Geodetic Survey on the day of the total solar eclipse May 28, rooo. 
The various phases of the oscillation did not take place at the different stations at the same absolute time, or local time, but in every instance were associated with the time of maximum obscuration of the sun. The duration of the oscillation was apparently about the same as that of the eclipse, about two and a half hours. The range of the oscillation was about one minute in arc for declination, and about eight units in the fifth decimal C.G.S. for horizontal intensity, that is, to about $\mathrm{I} / 2800$ th part of the absolute horizontal intensity. The general effect was to deflect the declination needle to the west, and decrease the horizontal intensity, before the time of maximum obscuration, the movement afterwards being in both cases in the opposite direction. The analysis indicates that the cause producing the magnetic oscillation was situated outside of the earth's crust, the presumption being very strong that the oscillation is to be referred to some change produced in the upper atmospheric regions by the abstraction of the sun's rays, due to interposition of the moon.

Dr. Bauer expresses himself as having been in doubt before making the observations as to whether any magnetic effect referable to the eclipse would reveal itself, and adds that he was afterwards slow to conclude that the magnetic oscillation observed was not accidentally connected with the eclipse, until he had made such exhaustive examination of every point involved as justified him in formulating a definite conclusion. The result is interesting, and makes it desirable, as he says, that every opportunity should in future be taken to obtain during eclipses, simultaneous magnetic, atmosphericelectric and meteorological observations at as many stations as possible.

It is to be remarked that, although Dr. Bauer eventually speaks with some confidence as to the magnetic movement observed having relation with the eclipse, the movement in question was small, and, abstractedly speaking, much too small on which to found any certain conclusion, considering the abundance of magnetic movements of similar and even greater magnitude. The circumstance that seems really to give weight to the conclusion drawn is the statement that the various phases of the magnetic oscillation were associated with the time of maximum obscuration of the sun. Confirmation of this circumstance is therefore what is now to be desired.

Following the paper there is printed an appeal for international co-operation in magnetic and allied observations during the total solar eclipse of May i 7 next.

\section{William Ellis.}

\section{PROF. H. A. ROWLAND.}

HENRY AUGUSTUS ROWLAND was born in H 1848 . He was educated as an engineer, and graduated at the Rensselaer Polytechnic at Troy, New York, in 1870 . After one year's experience as a railway engineer on the Western New York line, and a second spent as instructor in natural science at Wooster, Ohio, he returned to his college to share in its teaching, becoming an assistant professor in 1874 . Two years later, in 1876 , after spending a year under Helmholtz in Berlin he took office as the first professor of physics at the newly founded Johns Hopkins University. Baltimore remained his home until his death, on April I6, at the early age of fifty-three years.

His work at Berlin on the magnetic efforts due to a moving body when carrying an electric charge brought him at once into fame. The result was published by von Helmholtz in 1876 , and is thus described by Maxwell in a metrical letter to Tait, written in June, I877. Tait had inquired, also in verse, as to the electric effects to be expected if a disc of ebonite carrying a charge were made to rotate in its own plane, and Maxwell writes: NO. I 644, vOL. 64]
The mounted disk of ebonite

Has whirled before nor whirled in vain,

Rowland of Troy, that doughty knight,

Convection currents did obtain,

In such a disk, of power to wheedle

From its loved north the subtle needle.

Rowland showed by the direct effects produced on a magnetic needle that a charged body in motion gave rise to a magnetic field just as though it were a current whose strength depended on the product of the charge and the velocity.

This result is of fundamental importance to electrical theory; it was confirmed by Rowland and Hutchinson in 1889 , and has been generally accepted as an established fact. Within the last few months, however, Cremieu has published an account of a repetition of Rowland's experiments which has led him to a negative result ; the question just at the present moment appears to need further investigation.

Rowland's appointment at Baltimore was rapidly followed by a series of brilliant researches, each of the first importance. His determination of the unit of resistance came first. This was published in 1878 . The original B.A. units were constructed by the Electrical Standards Committee in $1863^{-4}$ to represent $10^{9}$ C.G.S. units of resistance ; according to Kohlrausch's results in 1870 they were 2 per cent. too high, while according to Lorenz (I873) they were 2 per cent. too low. Rowland's paper contains an able criticism of the old experiments and a detailed account of his own which led him to the number $9912 \times 10^{9}$ C.G.S. units as the value of the B.A. units. Further experiments in 1887 reduced this to $9864 \times 10^{5 *}$. The value now generally accepted is $98653 \times$ IO $^{9}$. Rowland himself employed a modification of Kirchhoff's original method, in which the induction current in a secondary circuit produced by reversing a measured primary current in a neighbouring circuit is observed.

In 1879 Rowland presented to the American Academy of Arts and Sciences his paper on the mechanical equivalent of heat, with subsidiary experiments on the variation of the mercurial from the air thermometer, and on the variation of the specific heat of water. To attempt to give any account of the contents of this classic work would occupy too much space. To appreciate its value and to realise the skill and the ingenuity of its author it must be studied itself. More is known now about exact thermometry and the precautions necessary in using a mercury thermometer, and so it has come about that some corrections are necessary in Rowland's work, specially in that part of it which deals with the relation between the scales of the mercury and the air thermometer. These corrections were made at the Johns Hopkins University by Messrs. Day and Wardner and Mallory; but this fact detracts nothing from the importance of his investigation, and among the many determinations of the value of Joule's equivalent, Rowland's will always remain in the first rank.

Passing over, for the present, much work of great value, among which we may note his investigations into the magnetic permeability of various substances, published in the Philosophical Magazine for 1873 and 1874 , and his theory of Hall's effect, we come next to the year 1882 , when Rowland gave to the Physical Society of London an account of his concave grating. This is published in the Philosaphical Magazine for September, 1883 .

The results of this discovery are well known. A new weapon was placed in the hands of spectroscopists; it became possible to photograph spectra directly without the use of prisms or lenses, and with a greatly increased dispersion and resolving power; the beautiful maps issued at a later date by Rowland himself, and by Higgs of Liverpool, are striking evidences of the value of the grating; the additions to our knowledge arising from this one discovery are already enormous; much has been achieved which, without it, would have been impossible. 